\title{
ANÁLISE DOS ASPECTOS ECONÔMICOS E AMBIENTAIS DA ATIVIDADE LEITEIRA EM PROPRIEDADES RURAIS DE UM MUNICÍPIO DA REGIÃO NORTE DO RIO GRANDE DO SUL
}

\author{
Cleusa Vicente Vargas ${ }^{1}$, Danni Maisa da Silva ${ }^{2}$, Divanilde Guerra ${ }^{2}$, Robson Evaldo Gehlen Bohrer ${ }^{2}$, \\ Mastrângello Enivar Lanzanova², Ramiro Pereira Bisognin ${ }^{2}$, Eduardo Lorensi de Souza², Guilherme \\ Eduardo Mörschbacher Gabriel ${ }^{3}$
}

\begin{abstract}
RESUMO - Com o desenvolvimento da bovinocultura de leite na Região Norte do Rio Grande do Sul (RS), várias questões ambientais tornam-se preocupantes. No entanto a gestão ambiental, como um dos pilares da sustentabilidade, pode propor medidas mitigadoras para amenizar os impactos ambientais e o uso consciente dos recursos naturais. Neste sentido, objetivou-se através do presente trabalho realizar uma análise dos aspectos econômicos e ambientais da atividade leiteira em propriedades rurais em um município da Região Norte do RS e apresentar orientações gerais para a mitigação dos riscos ambientais. Para tanto foi utilizada a metodologia de avaliação diagnóstica de dez propriedades rurais, no período de junho de 2016 a janeiro de 2017. Entre os principais resultados destaca-se que a atividade leiteira não possui licenciamento em nenhuma das propriedades rurais estudadas; em $60 \%$ das propriedades os dejetos são depositados diretamente no solo juntamente com a água e os resíduos da higienização da ordenha. Os animais em lactação, em $80 \%$ das propriedades, circulam livremente nas margens e leito de riachos; $60 \%$ dos entrevistados afirmam que as matas ciliares são fundamentais para preservar a qualidade dos recursos hídricos e dizem compreender a importância de preservar essas áreas. Com base nos resultados foi possível identificar os principais impactos da bovinocultura em relação ao ambiente, além de avaliar a importância dessa atividade para o desenvolvimento econômico das pequenas propriedades rurais da região.
\end{abstract}

Palavras chave: bovinocultura de leite, desenvolvimento econômico, impactos ambientais, sustentabilidade.

\section{ANALYSIS OF THE ECONOMIC AND ENVIRONMENTAL ASPECTS OF DAIRY ACTIVITY ON RURAL PROPERTIES OF A MUNICIPALITY OF THE NORTHERN REGION OF RIO GRANDE DO SUL}

\begin{abstract}
With the development of milk cattle in the Northern Region of Rio Grande do Sul (RS), several environmental issues become worrying. However, environmental management, as one of the pillars of sustainability, can propose mitigating measures to mitigate environmental impacts and the conscious use of natural resources. In this sense, the present work had the objective of analyzing the economic and environmental aspects of the dairy activity in rural properties in a municipality of the Northern Region of RS and presenting general guidelines for the mitigation of environmental risks. For this purpose, the methodology of diagnostic evaluation of ten rural properties was used in the period from June 2016 to January 2017. Among the main results it is highlighted that the milk activity does not have licensing in any of the rural properties studied; in 60\% of the properties the waste is deposited directly in the soil along with the water and the residues of the hygiene of the milking. Lactating animals, in $80 \%$ of the properties, circulate freely in the banks and bed of streams;
\end{abstract}

\footnotetext{
${ }^{1}$ Bióloga. Especialista em Gestão e Sustentabilidade Ambiental pela Universidade Estadual do Rio Grande do Sul - UERGS, Unidade em Três Passos.

${ }^{2}$ Professor (a) da UERGS, Unidade em Três Passos. Endereço para correspondência: Rua Cipriano Barata, $\mathrm{n}^{\circ} 211$. Bairro $^{2}$ Érico Veríssimo - Três Passos. CEP: 98600-000. Contato: (55) 3522-2895. E-mail: danni-silva@uergs.edu.br.

${ }^{3}$ Graduando do Curso de Bacharelado em Agronomia da UERGS, Unidade em Três Passos.
} 
$60 \%$ of respondents say that riparian forests are essential to preserve the quality of water resources and they say they understand the importance of preserving these areas. Based on the results, it was possible to identify the main impacts of cattle breeding in relation to the environment, besides evaluating the importance of this activity for the economic development of small rural properties in the region.

Keywords: dairy cattle, economic development, environmental impacts, sustainability.

\section{INTRODUÇÃO}

O leite é um alimento rico em fontes de nutrientes como proteínas, lipídeos, vitaminas e sais minerais (Stroeher et al., 2018), cuja produção tem aumentado sistematicamente no Brasil, nos últimos 50 anos (Vilela et al., 2017). No entanto, crescem também as preocupações mundiais sobre os problemas ambientais e a eficiência do uso dos recursos naturais em relação à produção animal (Janzen, 2011; Lesschen et al., 2011). A eficiência na gestão das atividades agropecuárias e do meio ambiente são os principais pilares da sustentabilidade econômica e ambiental da propriedade rural (Schaffer \& Procknow, 2002).

O aumento na produção de suínos e bovinos de leite nos últimos anos na Região Norte/Noroeste do Estado do Rio Grande do Sul (RS), bem como o manejo inadequado dos resíduos são um sinal de alerta e preocupação, devido às alterações provocadas nos ecossistemas naturais (Klauck, 2011). A produção leiteira nestas regiões tem se desenvolvido em função de vários atrativos, como clima, disponibilidade hídrica, estrutura fundiária dominada por pequenas propriedades, mão de obra familiar e acesso dos produtores a crédito subsidiado, especialmente via Programa Nacional de Fortalecimento da Agricultura Familiar (Pronaf) (Feix \& Leusin Júnior, 2015).

A região Sul, como todo o Brasil e outros países, teve um crescimento significativo na produção de leite nos últimos anos. De acordo com o Departamento de Agricultura dos Estados Unidos United States Department of Agriculture-USDA(2014), o crescimento para a produção de leite foi de 35,17 bilhões de litros, representando um aumento de $2,7 \%$ em relação à registrada no ano anterior. O Brasil ocupou a quinta posição no ranking mundial de produção de leite em 2014, atrás da União Europeia, Índia, Estados Unidos e China. A região Sul passou a ocupar, em 2014, a primeira posição no ranking das Grandes Regiões, com 34,7\% da produção nacional de leite. O RS teve um aumento de 176 milhões de litros na produção estadual, totalizando 4,685 bilhões de litros, enquanto o Paraná produziu
4,53 bilhões e cresceu 185 milhões litros, quando comparado a 2013. Estes representam os estados brasileiros com maior índice de crescimento na produção de leite (Zoccal \& Pereira, 2015).

Os Municípios da Região Norte do RS caracterizamse, na sua grande maioria, por serem essencialmente agrícolas e compostos de propriedades familiares (Feix \& Leusin Júnior, 2015). Segundo Derkoski (2004), as atividades desenvolvidas pelos agricultores familiares são as que mais se aproximam da natureza. Entretanto, as propriedades rurais com atividades agropecuárias também podem gerar impactos negativos ao meio ambiente, que vão desde o desmatamento de florestas para transformálas em áreas de pastagem (Cunha \& Guerra, 2009), uso indiscriminado do solo, insumos e de agrotóxicos, até o gerenciamento inadequado de dejetos e resíduos oriundos das atividades que potencializam alterações nos ecossistemas naturais, afetando tanto a fauna como a flora local (Do Carmo et al., 2002).

A partir do diagnóstico da realidade local, boas práticas agropecuárias que privilegiem os aspectos sociais, econômicos, culturais e ambientais podem ser sugeridas. Neste sentido, outros trabalhos já foram realizados com intuito de avaliar, discutir e elencar possíveis alternativas para amenizar os impactos ambientais com a produção de leite nas propriedades (Thomassen et al., 2008; Cunha \& Guerra, 2009; Castanheira et al., 2010; Fantin et al., 2012; Hermansen \& Kristensen, 2011). No entanto, a interação homem e natureza precisa ser repensada e reorganizada, e novos estudos precisam ser desenvolvidos. Nesse sentido, objetivou-se através deste trabalho realizar uma análise dos aspectos econômicos e ambientais da atividade leiteira em propriedades rurais de um município na Região Norte do RS e apresentar orientações gerais para a mitigação dos impactos ambientais em propriedades produtoras de leite.

\section{MATERIAL E MÉTODOS}

No presente estudo foi utilizada uma metodologia exploratória qualitativa e quantitativa para analisar a 
situação apresentada em dez propriedades rurais em um município da Região Norte do Estado do Rio Grande do Sul. Foram realizadas visitas de acompanhamento em dez propriedades rurais selecionadas com atividades de bovinocultura leiteira. Para tanto foi realizada investigação in loco dos aspectos ambientais, no período de junho de 2016 a janeiro de 2017.

Utilizou-se como instrumento de pesquisa a aplicação de entrevistas semiestruturadas com os membros da família, para a caracterização dos aspectos ambientais, sociais e econômicos da propriedade rural. A entrevista teve como foco principal a gestão da propriedade em relação às questões ambientais, licenciamento da atividade de bovinocultura leiteira, conhecimento do produtor sobre as leis ambientais, cuidados com o solo, uso da água e preservação dos recursos hídricos, manutenção das áreas de preservação permanentes (APPs) e de reserva legal (RL), bem como manejo dos dejetos e uso de agrotóxicos.

Para a escolha das propriedades foram considerados os seguintes critérios: (I) ser de agricultura familiar (propriedade em média de 10 a 30 hectares e mão de obra familiar); (II) ter a atividade de bovinocultura leiteira como a principal fonte de renda da propriedade; (III) ter uma produção média acima de 100 litros de leite por dia; (IV) ter em média de 10 a 50 animais em lactação; (V) ter realizado o Cadastro Ambiental Rural (CAR).

Foram realizadas três visitas em cada propriedade com vistas no acompanhamento das atividades e aplicação das entrevistas. Nas visitas foram observadas e registradas as características gerais das propriedades, especialmente relacionadas com a atividade em análise. Na realização das entrevistas participaram todos os membros das famílias presentes nas propriedades, vinculados à produção leiteira. Para fins de apresentação das informações coletadas, evitando-se a identificação dos produtores entrevistados, estes estão representados por números ordinais (Produtor 1; Produtor 2;...; Produtor 10). Os dados foram analisados e organizados em gráficos de porcentagem utilizando-se o software Excel.

\section{RESULTADOS E DISCUSSÃO}

Em relação à gestão da propriedade e da produção de leite, as dez unidades estudadas apresentaram como característica comum o fato de fazerem parte da rede de acompanhamento realizada pelo Escritório Municipal da Emater/RS-Ascar e pelas Secretarias de Agricultura e Meio Ambiente do Município em estudo, através de assessoria técnica para a gestão financeira e da produção nas propriedades. Acompanhar o processo de gestão da produção de leite é importante para conhecer o que os bovinocultores pensam, sentem e como percebem as problemáticas ambientais.

A produção diária de leite nas dez propriedades pesquisadas variou de 100 a 400 litros, enquanto que o valor médio pago pela indústria, por litro, variou de $\mathrm{R} \$ 0,95$ a 1,50. Esta diferença de valor é decorrente da oferta das empresas que adquirem o leite na região, podendo variar conforme a disponibilidade, quantidade fornecida e a qualidade do produto. Segundo Brito et al. (2011), a produção de leite sofreu influência de vários fatores como: desenvolvimento tecnológico nos sistemas de produção, melhoramento genético dos animais e instalações de novas indústrias.

No que se refere ao licenciamento, das dez propriedades visitadas nenhuma possui licença ambiental para exercer a atividade de produção de leite. Este é um dos aspectos que merecem atenção e devem ser corrigidos no intuito de garantir a adequada execução das atividades nas propriedades, sem riscos de danos ambientais. Segundo a Resolução do Conselho Nacional do Meio Ambiente (CONAMA) nº 237, de 19 de dezembro de 1997, por meio do licenciamento ambiental o órgão público responsável tem a competência de licenciar a localização, instalação, ampliação e a operação de empreendimentos e atividades que utilizam os recursos ambientais e são consideradas potencialmente poluidoras, ou ainda, aquelas que possam causar impactos negativos ao ambiente natural, como o caso da bovinocultura de leite.

Nesse mesmo sentido, Milaré (2013) destaca que a licença ambiental é fundamental para garantir a sustentabilidade nos ecossistemas naturais, além de servir como instrumento de controle para o Poder Público, sob forma de imposição à responsabilidade com o meio ambiente, em que as atividades potencialmente poluidoras devem adotar critérios estabelecidos pela legislação vigente. Logo, a bovinocultura leiteira pode provocar alterações ambientais, de modo que, sem o acompanhamento e vistoria por parte dos órgãos ambientais, a atividade pode desencadear sérios desequilíbrios no bioma natural. 
Quando questionados sobre o conhecimento em relação às leis ambientais, todos os produtores rurais entrevistados responderam ter conhecimento. No entanto, um dos produtores, identificado apenas como Produtor 1 informou que "em alguns casos a produção se torna economicamente inviável se todas as normas legais forem cumpridas". Esta abordagem apresentada pelo Produtor 1 refere-se especialmente às exigências legais em relação às Áreas de Preservação Permanentes (APPs), mata ciliar, e manejo dos dejetos e resíduos da produção.

Em relação ao processo de manejo e viabilidade econômica da produção, os entrevistados de todas as propriedades rurais entrevistadas informaram que para a adequação e o balanceamento nutricional dos animais em lactação, desde a definição das áreas dos piquetes, a determinação da lotação de animais, o tempo de permanência em cada piquete, ou seja, a definição da melhor estratégia de uso e rodízios entre os piquetes têm o acompanhamento técnico da Secretaria da Agricultura e Meio Ambiente do Município e Emater/ RS-Ascar, que prestam a devida assessoria técnica, bem como orientação sobre a adubação necessária e produção de silagem.

Em cinco propriedades que recebem assessoria técnica existe ainda a colaboração do departamento técnico de uma cooperativa da região, que realiza o acompanhamento do cultivo das pastagens e manejo do solo. Esse acompanhamento, realizado por técnicos agropecuários e agrônomos, pode explicar os dados positivos em relação ao uso do solo nessas propriedades. Em $60 \%$ das propriedades, os produtores afirmaram que adotam o sistema de plantio direto, e cuidam para evitar as perdas de solo por meio de barreiras vegetais em áreas declivosas, além de realizarem o planejamento da produção de grãos e pastagens, buscando a conservação do solo das áreas cultivadas.

No entanto, pode-se observar que a maioria das áreas é cultivada, principalmente, com a cultura do milho para silagens, sendo estas áreas, em geral, bastante declivosas, o que pode potencializar os efeitos do processo de degradação e perdas de solo provocadas pela erosão. A perda do solo pela erosão causa prejuízos ambientais e econômicos, o manejo inadequado com a retirada da cobertura vegetal e exposição da camada superficial sob a ação dos ventos, do sol e da chuva, fazem com que boa parte dos nutrientes seja transportado pelas águas (Guth, 2010).
A Figura 1 apresenta a fonte de dessedentação animal nas propriedades rurais pesquisadas.

Conforme a Figura 1, em relação às condições de acesso dos animais aos recursos hídricos, $80 \%$ dos proprietários responderam que os animais têm livre acesso aos cursos hídricos da propriedade. Neste contexto, o fator mais preocupante é que em todas as propriedades banhadas por cursos hídricos os animais têm livre acesso à água, onde podem realizar suas necessidades fisiológicas, ou até mesmo provocarem o assoreamento das margens. Em 10\% das propriedades os animais dispõem de bebedouros próprios e, no restante, os animais utilizam açude como fonte de dessedentação.

De acordo com Matos (2002), a água é o alimento de maior requisição quantitativa para o gado de leite. Vacas em lactação necessitam de mais água em relação a seu peso vivo do que outros animais, pois o leite contém $87 \%$ de água. O corpo de um bovino adulto é constituído de 55 a 70\% de água, variando de 80 a $85 \%$ no animal jovem e até $90 \%$ no recém-nascido. Em sistemas de produção de leite, não basta ter água na propriedade, é preciso que sejam atendidos alguns parâmetros de potabilidade, com baixos níveis de sólidos e de alcalinidade, além da ausência de compostos tóxicos, a fim de não comprometer a saúde do gado e manter a qualidade do leite produzido (Prado et al., 2010). Nesse sentido a análise e o tratamento da água são aspectos que devem ser considerados nas propriedades dos produtores rurais entrevistados.

Em pesquisa realizada por Capoane (2008) no município em estudo, foram encontradas amostras de água contaminadas com coliformes fecais. Com base

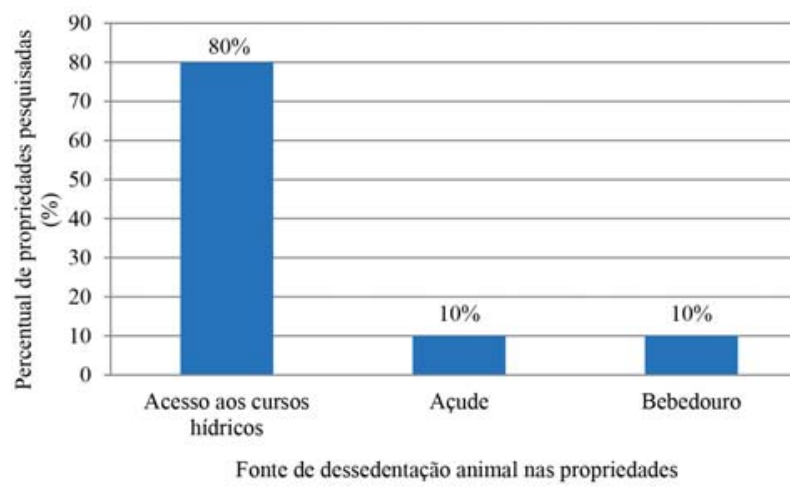

Figura 1 - Fonte de dessedentação aos animais nas propriedades pesquisadas, 2017. 
nesta informação, toda a água disponibilizada aos animais deveria passar por algum tipo de tratamento, porém em apenas $20 \%$ das propriedades é realizado algum tipo de tratamento simplificado (cloração), conforme informações prestadas pelos produtores. Sendo assim, a parceria entre o poder público e os bovinocultores é fundamental, para que sejam realizadas análises da qualidade da água utilizada nas propriedades rurais, tanto para o consumo humano, quanto dos animais e higienização dos equipamentos da ordenha, com vistas na saúde daqueles que a consomem.

A qualidade do leite produzido depende de vários fatores, da saúde dos animais, da limpeza dos equipamentos e, principalmente, da potabilidade da água utilizada na propriedade. Além disso, o uso da água contaminada pode trazer sérios riscos à saúde, transportando agentes patogênicos para animais e humanos (Amaral et al., 2003). Várias bactérias, verminoses e vírus podem infectar os animais pelas águas contaminadas, podendo ocasionar prejuízos econômicos para o produtor rural. Uma das doenças que causa preocupação entre os produtores de leite é a mastite, cuja transmissão dos agentes causadores pode acontecer pela água e pela higienização inadequada dos instrumentos de ordenha (Guerra et al., 2011). A bactéria Staphylococcus aureus aparece entre os agentes patogênicos que mais está presente nos casos de mastite bovina (Guerra et al., 2011). As cepas da S. aureus podem estar na água utilizada nas propriedades representando um risco para a contaminação do animal e à saúde humana. Existe então, a real preocupação com a desinfecção e controle da qualidade da água utilizada na produção de leite (Amaral et al., 2003). A água contaminada também pode ser uma fonte de Pseudomonas spp., coliformes e outras bactérias Gramnegativas (Chambers, 2005).

Neste contexto, a Lei n ${ }^{\circ}$ 9.433/1997, que institui a Política Nacional dos Recursos Hídricos (PNRH), define as diretrizes sobre a gestão dos recursos hídricos com enfoque democrático e sustentável, além disso, aborda os aspectos ecológicos em perigo e busca o equilíbrio entre o desenvolvimento socioeconômico e ambiental (Brasil, 1997). Outro ponto importante na Política Nacional de Recursos Hídricos é a outorga do direito de uso dos recursos hídricos, que objetiva "assegurar o controle quantitativo e qualitativo dos usos da água, superficiais ou subterrâneas", no qual o outorgado precisa esclarecer a finalidade e a quantidade do recurso utilizado (Brasil, 1997). Essas informações são importantes para o controle dos recursos disponíveis. No Art. $1^{\circ}$, a PNRH considera a água como um recurso natural e limitado, dotado de valor econômico, um bem de domínio público e em situações de escassez determina que, o uso deve ser prioritário dos recursos hídricos para o consumo humano e a dessedentação dos animais (Brasil, 1997).

Diante da redução da qualidade da água evidenciada pelos mais diversos usos (Barbosa, 2008), algumas medidas são necessárias para controlar, orientar e avaliar a gestão das atividades desenvolvidas na bovinocultura, para amenizar os impactos aos recursos hídricos. Entre estas pode ser citado o uso das cisternas para captação de água da chuva e implantação de bebedouros aos animais, evitando o acesso aos cursos hídricos naturais e, consequentemente, a contaminação e o assoreamento dos mananciais. Estas são medidas necessárias, além de se fazer a análise físico-química e bacteriológica da água consumida pelos animais e usada no manejo na ordenha. Segundo Guerra et al. (2011), a análise físico-químico da água, para potabilidade, deve incluir, obrigatoriamente, a verificação dos parâmetros de turbidez, cor, $\mathrm{pH}$, sólidos totais dissolvidos, dureza, ferro, manganês, sulfatos, nitrogênio amoniacal. Havendo a necessidade, deve se proceder ao tratamento adequado da água para as atividades de ordenha, bem como da água disponibilizada aos animais, uma vez que essa influencia na qualidade do produto gerado, e na saúde do rebanho (Leite et al., 2003; Reinemann et al., 2003; Elmoslemany, 2010).

Em relação às áreas protegidas por Lei, a Figura 2 apresenta o percentual das propriedades pesquisadas que conservam as APPs e matas ciliares.

Conforme a Figura 2, em $80 \%$ das propriedades entrevistadas as Áreas de Preservação Permanente (APPs) são mantidas conservadas. Tal fato pode estar associado às condições de relevo das propriedades, já que, na maioria, as áreas são de difícil acesso e bastante declivosas. Esta informação também é descrita por Coelho \& Graneell-Pérez (2000), que afirmaram que a declividade do terreno influencia na permanência da cobertura florestal e na faixa de mata ciliar.

Destaca-se que o Código Florestal, através da Lei 12.651/2012, exige a manutenção das APPs com base na sua função protetora e relevância ecológica, além da sua função ambiental de preservar os recursos hídricos, 


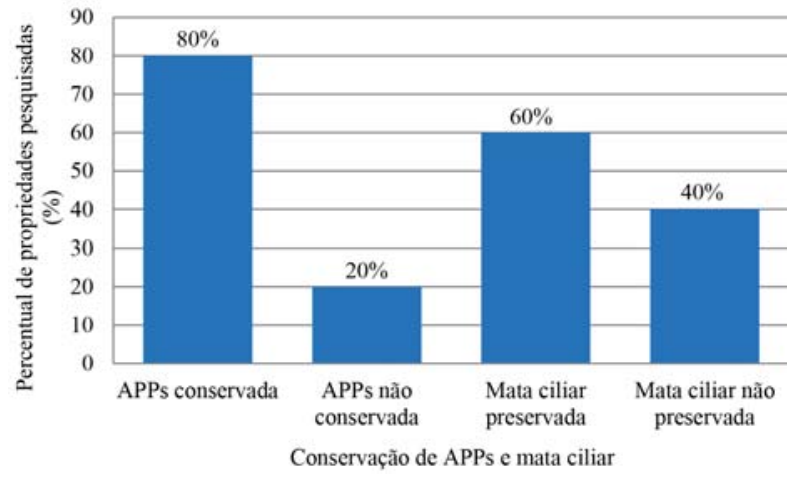

Figura 2 - Propriedades rurais pesquisadas em que os agricultores conservam APPs e mata ciliar, 2017.

a paisagem, a estabilidade geológica, a biodiversidade e o fluxo gênico de flora e fauna, bem como proteger o solo, e assegurar o bem-estar das populações humanas. Nesse sentido, a floresta deverá ser mantida em sua integridade sendo vetada qualquer exploração econômica, cobertas ou não por vegetação nativa, mesmo que a floresta nativa tenha sido suprimida, a área por si só é local de preservação, uma vez que desempenha papel fundamental de proteção das águas e do solo (Machado, 2009).

É importante destacar as considerações de Gass (2010), ao afirmar que a atividade de produção leiteira é uma das formas de pressão sobre os recursos naturais, devido à transformação das matas ciliares em potreiros, trazendo consequências de desestabilização dos barrancos das sangas, arroios e rios da região noroeste do RS.

Em seis das propriedades deste estudo, existem áreas de mata ciliar protegendo o leito dos riachos e córregos. Segundo Prado et al. (2010), a mata ciliar desempenha um papel ecológico fundamental no ecossistema aquático e terrestre, além de reduzir o carreamento de partículas do solo e de outros compostos poluentes para os cursos de água.

Segundo Souza (2012), as matas ciliares atuam como importantes barreiras de sedimentos, pois funcionam como filtros, melhorando a qualidade da água. Ainda segundo Souza (2012), as matas ciliares são fundamentais para evitar a erosão, uma vez que contribuem para infiltração de água no solo, influenciando no ciclo hidrológico regional e na vazão dos rios. Logo, sua preservação reduzirá o aporte de efluentes e dejetos aos cursos d'água, o que poderia comprometer a autodepuração dos cursos hídricos e sua função ecológica.

Na questão relacionada ao manejo dos dejetos provenientes da atividade da bovinocultura leiteira, todas as propriedades analisadas não possuem locais próprios e adequados para o armazenamento, tanto dos resíduos líquidos como dos resíduos orgânicos da produção de leite. Em 40\% dos casos, os dejetos são retirados da sala de espera (local em que os animais em lactação ficam antes da ordenha), e da sala de alimentação, onde tem a maior concentração e volume, e são levados diretamente para as pastagens. De acordo com Konzen \& Alvarenga (2005), os dejetos líquidos de bovinos são comprovadamente eficientes na produção de grãos, e forrageiras, como também a utilização do composto orgânico em aplicação equivalente a 100\% da adubação química foi eficiente na produção de milho. Contudo, a aplicação direta dos dejetos no solo, sem estabilização prévia, pode desencadear elevado risco de contaminação, principalmente, por agentes microbiológicos. Ressalta-se, ainda, a necessidade de análise tanto dos dejetos quanto da área agrícola que será utilizada para disposição do material.

Em todas as propriedades entrevistadas, os dejetos são lançados no solo nas proximidades das estrebarias, provocando grandes atoleiros que dificultam o próprio deslocamento dos animais (Figura 3). Em tais situações é importante e urgente o manejo adequado dos dejetos, desde a impermeabilização da área, coleta dos dejetos e estabilização em sistemas biológicos de tratamento. O mesmo é válido para o efluente resultante da lavagem dos equipamentos.

Conforme estudos de Klauck (2011), somente com a sensibilização do produtor em relação à importância da preservação do meio ambiente e com auxílio técnico, financeiro e social dos órgãos governamentais que se reduzirá o dano ambiental que a bovinocultura leiteira vem causando ao meio ambiente, uma vez que o desenvolvimento econômico deve levar em consideração as questões ambientais, para permitir a preservação da diversidade e que as gerações futuras encontrem um ambiente favorável à vida.

Ao serem questionados sobre o armazenamento e descarte das embalagens vazias de medicamentos e produtos veterinários, em $70 \%$ das propriedades, esses materiais são descartados junto com o lixo comum. 


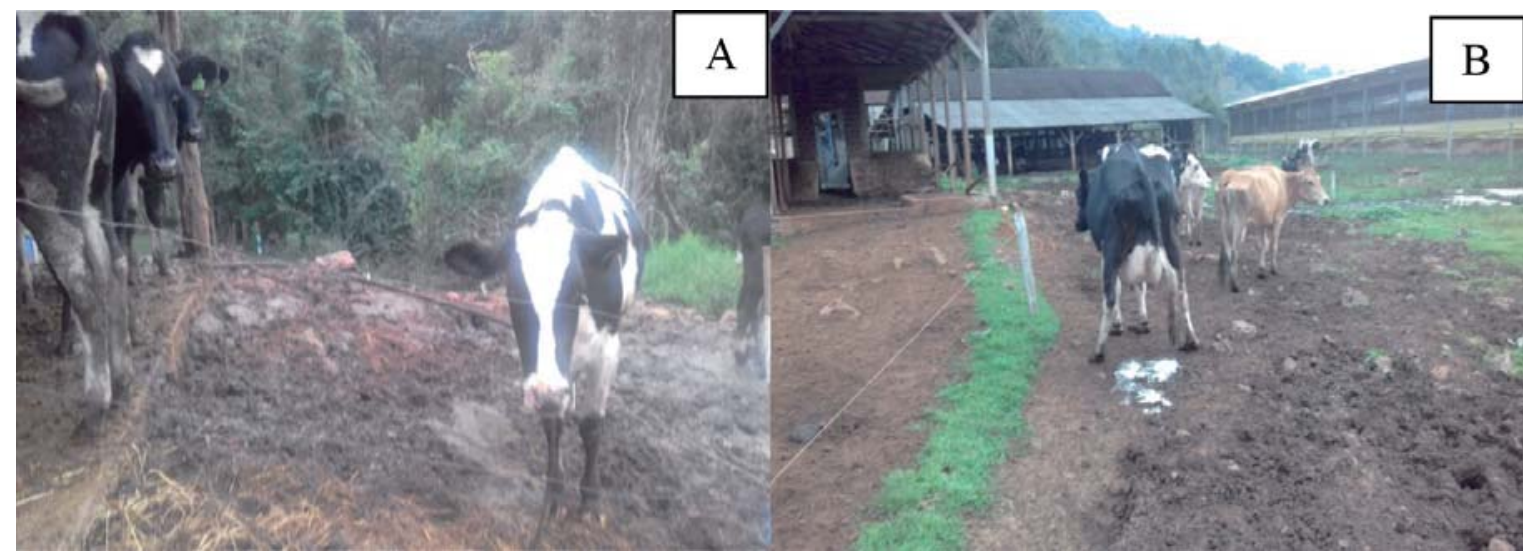

Figura 3 - Imagens dos dejetos lançados diretamente ao solo, próximo à sala de ordenha (A) e estrebarias (B), nas propriedades rurais pesquisadas, 2017.

Fonte: Autores (2017).

Desses, $40 \%$ dos produtores rurais informaram que os resíduos são recolhidos pelo caminhão do lixo, e o restante relataram enterrar os resíduos. Este dado é extremamente preocupante, tendo em vista o desconhecimento dos possíveis danos e comportamento dos compostos no meio ambiente. Outras três famílias, que também são produtoras de suínos, entregam esses resíduos para a empresa responsável pela parceira na produção de suínos.

Conforme a Resolução RDC no 306/2004, “compete à Vigilância Sanitária dos Estados, dos Municípios e do Distrito Federal, com o apoio dos Órgãos de Meio Ambiente, de Limpeza Urbana, e da Comissão Nacional de Energia Nuclear (CNEN), divulgar, orientar e fiscalizar" o cumprimento das normas legais sobre o gerenciamento e descarte dos Resíduos Sólidos da Saúde (RSS). O Plano de Gerenciamento de Resíduos de Serviços de Saúde (PGRSS) deve seguir as normas locais, de acordo com a coleta, transporte e disposição final dos resíduos gerados. Os cuidados com o armazenamento e descarte, principalmente dos medicamentos de uso veterinário, são fundamentais para evitar a contaminação do solo e da água. Nesse sentido, seria de extrema importância a realização de campanhas de esclarecimento e coletas desses materiais, pelos órgãos competentes, uma vez que o descarte do RSS em locais inadequados compromete a saúde da população.

Outro fator preocupante observado nas visitas é o descarte das embalagens de agrotóxicos que, em muitas propriedades, acaba ficando em locais inadequados. Em algumas, as embalagens são armazenadas em galpões, sendo o local comum onde fica a ração, o milho e em alguns casos o feno para a alimentação dos animais. Nenhuma das propriedades entrevistadas informou que realiza a devolução das embalagens para a empresa que comercializou o produto. Este é um tema que necessita ser trabalhado com os produtores rurais para o atendimento da legislação vigente (Brasil, 2000; Brasil, 2010).

Com o objetivo de maximizar a produção e aumentar os lucros, o uso dos agrotóxicos na produção de alimentos e o crescente uso de pesticidas nos animais (carrapaticida, inseticida, vermífugos), desestabiliza o equilíbrio ecológico e, consequentemente, influencia no surgimento de outras espécies de "pragas" mais resistentes (Furlong et al., 2007). Para o armazenamento, transporte e comercialização de agrotóxicos em todo o território brasileiro foi criada a Lei Federal n. ${ }^{\circ}$ 9.974, de 06 de junho de 2000 (Brasil, 2000) e o Decreto n. ${ }^{\circ}$ 4.074, de 08 de janeiro de 2002 (Brasil, 2002). Contudo, a devolução das embalagens de agrotóxicos ao ponto de comercialização está prevista no Art. 33, que trata da logística reversa, da Lei Federal n ${ }^{\circ}$. 12.305/2010, a qual institui a Política Nacional de Resíduos Sólidos (Brasil, 2010).

\section{CONSIDERAÇÕES FINAIS}

Os resultados da pesquisa levaram a compreensão de que a produção de leite pode causar vários impactos ao meio ambiente. As observações nas propriedades 
rurais evidenciaram a falta de locais adequados para disposição dos dejetos produzidos pelos animais, áreas degradadas próximas ao leito dos córregos e riachos devido à falta de mata ciliar e livre acesso dos animais ao rio e a necessidade de orientação e acompanhamento em relação aos cuidados com o uso de agrotóxicos.

Nesse contexto, fica evidente a necessidade de suporte técnico ambiental para a melhoria da gestão das propriedades rurais pesquisadas, que representam a realidade da maioria das pequenas propriedades da região. Dentre os procedimentos para a redução dos impactos sugere-se a construção de bebedouros para o gado e cercamento dos limites da propriedade para evitar o acesso do gado aos cursos hídricos, o que possibilitará também a reconstituição da mata ciliar e das APPs. Fica evidente a necessidade de construção de esterqueiras ou sistemas para tratamento dos dejetos dos animais, além de incentivo à produção com menor impacto.

O uso de dejetos de bovinos na lavoura para a produção de grãos ou de pastagens pode ser considerada uma alternativa promissora de adubação e redução dos custos de produção, contudo, deve receber acompanhamento para a disposição adequada e compatível a capacidade de absorção dos solos da região.

Ressalta-se que a produção de leite para as famílias pesquisadas representa além de desenvolvimento, a conquista aos direitos legais de todos os cidadãos como: moradia, alimentação, vida digna com acesso a serviços de saúde e educação. A renda obtida garante inclusive a formação superior dos filhos.

Desta forma, através das informações levantadas é possível inferir que a produção de leite na região estudada necessita de orientação técnica para minimizar os efeitos negativos da atividade sobre o meio ambiente, compatibilizando geração de renda às famílias e qualidade ambiental. Por esse motivo, sugere-se o desenvolvimento de novos estudos para avaliar a possível contaminação das águas superficiais e subterrâneas na região, bem como a capacidade de absorção dos dejetos bovinos pelo solo, sem que haja riscos ao meio ambiente e à população.

\section{LITERATURA CITADA}

AMARAL, L. A.; ROSSI JÚNIOR, O. D.; NADER FILHO, A. et al., Ocorrência de Staphylococcus sp. em água utilizada em propriedades leiteiras do Estado de São Paulo. Arquivo Brasileiro de Medicina

Veterinária e Zootecnia, v. 55, n. 5, p. 620-623, 2003.
BARBOSA, G. S. O desafio do desenvolvimento sustentável. Revista Visões 4ª Edição, Nº4, v. 1 - Jan/Jun, 2008.

BRASIL. Constituição. Constituição da República Federativa do Brasil. Brasília: Senado, 1988. BRASIL. LEI No 9.433, de 08 de janeiro de 1997. Institui a Política Nacional de Recursos Hídricos, cria o Sistema Nacional de Gerenciamento de Recursos Hídricos. 1988. In: http:// www.planalto.gov.br/ccivil 03/Leis/19433.htm (acessado em 25 de julho de 2017).

BRASIL. Lei ${ }^{\circ}$ 9.433. Institui a Política Nacional de Recursos Hídricos, cria o Sistema Nacional de Gerenciamento de Recursos Hídricos, regulamenta o inciso XIX do art. 21 da Constituição Federal, e altera $\mathrm{o}$ art. $1^{\circ}$ da Lei $\mathrm{n}^{\circ} 8.001$, de 13 de março de 1990, que modificou a Lei ${ }^{\circ} 7.990$, de 28 de dezembro de 1989. 1997. In: http:// www.planalto.gov.br/ccivil_03/leis/19433.htm (acessado em: 18 novembro de 2017).

BRASIL. Lei $n^{\circ}$ 9.974. 2000. Altera a Lei $n^{\circ} 7.802$, de 11 de julho de 1989, que dispõe sobre a pesquisa, a experimentação, a produção, a embalagem e rotulagem, o transporte, o armazenamento, a comercialização, a propaganda comercial, a utilização, a exportação, o destino final dos resíduos, o controle, a inspeção e a fiscalização e dá outras providências. Diário Oficial da República Federativa do Brasil. Brasília, dofc 07/06/2000, pág. 000001, col. 1.2000. In: http://www.planalto.gov.br/ccivil_03/ Leis/L7802.htm (acessado em 25 de julho de 2017).

BRASIL. Agência Nacional de Vigilância Sanitária. Resolução RDC n ${ }^{\circ}$ 306, de 07 de dezembro de 2004. Dispõe sobre o Regulamento Técnico para o gerenciamento de resíduos de serviço de saúde.

Diário Oficial da República Federativa do Brasil, Brasília, DF, dezembro. 2004. In: https://www.diariodasleis.com.br/busca/ exibelink.php?numlink=1-9-34-2004-12-07-306 (acessado 25 de agosto de 2017).

BRASIL. Plano Nacional de Recursos

Hídricos. Síntese Executiva - português / Ministério do Meio Ambiente, Secretaria de Recursos Hídricos - Brasília: MMA, 135p. 2006. In: http://www.mma.gov.br/agua/recursos-hidricos/ plano-nacional-de-recursos-hidricos (acessado em 25 de julho de 2017). 
BRASIL. Política Nacional de Resíduos Sólidos. Lei $n^{\circ}$. 12.305, de 2 de agosto de 2010 . Institui a Política Nacional de Resíduos Sólidos; altera a Lei $\mathrm{n}^{\circ}$ 9.605, de 12 de fevereiro de 1998; e dá outras providências. 2010. In: http:// www.planalto.gov.br/ccivil_03/_ato2007-2010/2010/ lei/112305.htm (acessado em $1 \overline{8}$ outubro de 2017).

BRITO, L. G.; MARCOLAN, A. L.; SALMAN, A. K. D. et al. Sistemas de produção de leite para Rondônia. Porto Velho, RO: Embrapa Rondônia, 2011.72 p.

CAPOANE, V. Poluição hídrica por dejetos de suínos: um estudo de caso na microbacia do Arroio Caldeirão Palmitinho - RS, 2008. 87 f. Trabalho de graduação B (Curso de Geografia) - Universidade Federal de Santa Maria, 2008.

CASTANHEIRA, É. G.; DIAS, A. C.; ARROJA, L. et al., The environmental performance of milk roduction on a typical Portuguese dairy farm. Agricultural Systems, v. 103, n. 7, p. 498-507, 2010.

CHAMBERS, J. V. The microbiology of raw milk. Dairy microbiology handbook: the microbiology of milk and milk products. John Wiley \& Sons, Hoboken, NJ, USA, 2005 p. 39-90.

COELHO, G. C.; GRANEELL-PÉREZ, M. C. Mata ciliar e o desmatamento no noroeste do RS. In: SEMINÁRIO ESTADUAL DE REFLORESTAMENTO E RECUPERAÇÃO AMBIEntal. Anais do I Seminário Estadual. Ed. Unijuí. Ijuí, 2000.

Conselho Nacional de Meio Ambiente (CONAMA). Resolução n ${ }^{\circ} 237$, de 19 de dezembro de 1997. 1997. In: http:// www.mma.gov.br/port/conama/res/res97/ res23797.html (acessado em 13 janeiro de 2017.

Conselho Nacional de Meio Ambiente (CONAMA). Resolução $n^{\circ} 357$, de 17 de março de 2005. 2005. In: www.mma.gov.br/port/conama/res/res05/ res35705.pdf (acessado em 13 janeiro 2017).

CUNHA, S. B; GUERRA, A. J. T. Avaliação e perícia ambiental. 9. ed. Rio de Janeiro: Bertrand Brasil, 2009.
DERKOSKI, J. L. Agricultura Familiar: Paradigma para o Desenvolvimento Sustentável. Educação e Socioeconômica Solidária: Série Sociedade Solidária, v. 1, p. 310-331, 2004.

DO CARMO, R. L; GUIMARÃES, E.; DE AZEVEDO, A. M. M. Agroindústria, população e ambiente no sudoeste de Goiás. In: XIII Encontro da Associação Brasileira de Estudos Populacionais, 2002. Anais... Ouro Preto, Minas Gerais, 2002. p. 1-23.

DUINKER, P.; WIERSMA Y. F.; HAIDER, W. et al. Protected areas and sustainable forest management: What are we talking about? The Forestry Chronicle, v. 86, n. 2, p. 173-177, 2010.

EDWARDS, D. P.; FISHER, B.; WILCOVE, D. S. High conservation value or high confusion value? Sustainable agriculture and biodiversity conservation in the tropics. Conservation Letters, v. 5, n. 1, p. 20-27, 2012.

ELMOSLEMANY, A. M.; KEEFE, G. P.; DOHOO, I. R. et al. The association between bulk tank milk analysis for raw milk quality and on-farm management practices. Preventive veterinary medicine, v. 95, n. 1, p. 32-40, 2010 .

ESTADOS UNIDOS. Department of Agriculture. USDA. Gov - United States Department of Agriculture. 2014. In: http://www.usda.gov (acessado em 25 novembro 2016).

FANTIN, V.; BUTTOL, P.; PERGREFFI, R. et al. Life cycle assessment of Italian high quality milk production. A comparison with an EPD study. Journal of cleaner production, $v$. 28, p. 150-159, 2012.

FEIX, R. D.; LEUSIN JÚNIOR, S. Painel do agronegócio no Rio Grande do Sul: 2015. Porto Alegre: FEE. 2015. In: https://www.fee.rs.gov.br/ wp-content/uploads/2015/09/20150903painel-doagronegocio-no-rs-2015.pdf (acessado em 03 de agosto de 2017).

FURLONG, J.; MARTINS, J. R.; PRATA, M. C. A. O carrapato dos bovinos e a resistência: temos o que comemorar. A Hora Veterinária, v. 27, n. 159 , p. 26-32, 2007. 
GASS, S. L. B. Áreas de preservação permanente (APPs) e o planejamento do seu uso no contexto das bacias hidrográficas: metodologia para adequação dos parâmetros legais. (Dissertação: Mestrado em Geografia). Porto Alegre: UFRGS/PPGEA. 2010.

GUERRA, M. G.; GALVÃO JÚNIOR, J. G. B.; RANGEL, A. H. $\mathrm{N}$ et al. Disponibilidade e qualidade da água na produção de leite. Natal/

RN. Acta Veterinária Brasílica, v. 5, n. 3, p. 230-235, 2011.

GUTh, P. L. Perdas de solo e água por erosão hídrica em sistemas de culturas oleaginosas / Paulo Luís Guth. Santa Maria, 2010. 83 f. Dissertação (mestrado em ciência do solo) - Universidade Federal de Santa Maria, Centro de Ciências Rurais, Programa de Pós-graduação em Ciência do Solo, 2010.

HERMANSEN, J. E.; KRISTENSEN, T. Management options to reduce the carbon footprint of livestock products. Animal Frontiers, v. 1, n. 1, p. 33-39, 2011.

JANZEN, H. H. What place for livestock on a re-greening earth? Animal Feed Science and Technology, v. 166, p. 783-796, 2011.

KLAUCK, J. B. Impacto agroeconômico da adequação da agricultura de Nova Ramada - RS à Legislação de APPs e Reserva Legal. Dissertação (mestrado em Pós-Graduação Stricto Sensu em Desenvolvimento). Universidade Regional do Noroeste do Estado do Rio Grande do Sul Unijuí, 2011.

KONZEN, E. A.; ALVARENGA, R. C. Manejo e utilização de dejetos animais: aspectos agronômicos e ambientais. Ministério da Agricultura, Pecuária e Abastecimento. Sete Lagoas: Circular Técnica, v. 63, p. 65, 2005.

LEITE, M.O.; ANDRADE, N. J.; FONSECA, L. M. et al. Controle de qualidade da água em indústrias de alimentos. Revista Leite e Derivado, v. 69, p. 38-45, 2003.
LESSCHEN, J. P.; VAN DEN BERG, M.; WESTHOEK, H. J. et al. Greenhouse gas emission profiles of European livestock sectors. Animal Feed Science and Technology, v. 166, p. 16-28, 2011.

MACHADO, P. A. L. Direito dos cursos de água internacionais. Malheiros. São Paulo, 2009.

MATOS, L. D. Estratégias para redução do custo de produção de leite e garantia de sustentabilidade da atividade leiteira. Simpósio sobre Sustentabilidade da Pecuária Leiteira na Região Sul do Brasil, p.156-183, 2002.

MILARÉ, É. Direito do ambiente. $8^{\text {a }}$ ed. São Paulo: ed. Revista dos Tribunais, p. 776-832, 2013.

PNUD. Programas das Nações Unidas para o Desenvolvimento. Objetivos do Desenvolvimento do Milênio apregoados pelo PNUD. 2005. In: www.pnud.org.br/odm/ (acessado em 16 de agosto de 2016).

REINEMANN, D. J.; WOLTERS, G.; BILLON, P. et al. Review of practices for cleaning and sanitation of milking machines. Bulletin-

International Dairy Federation, p. 3-18, 2003.

PRADO, R. B.; TURETTA, A. P. D.; ANDRADE, A. G. Manejo e conservação do solo e da água no contexto das mudanças ambientais. Embrapa Solos, Rio de Janeiro, 491 p., 2010.

SOUZA, M. C. B. Influência da mata ciliar na qualidade da água de trecho do rio Jacarecica - Dissertação (Mestrado em Recursos Hídricos e Saneamento) Universidade Federal de Alagoas. Maceió/AL. 195 f, 2012.

STROEHER, F. H.; CLASEN, B. E.; SILVA, D. M. et al. Qualidade do leite: visão de produtores rurais do município de São Martinho - RS.

Revista Brasileira de Agropecuária Sustentável (RBAS), v. 7, n. 4, p.88-94, Dez., 2017. 
THOMASSEN, M. A.; VAN CALKER, K. J.; SMITS, M. C. J. et al. Life cycle assessment of conventional and organic milk production in the Netherlands. Agricultural systems, v. 96, n. 1, p. 95-107, 2008.

VILELA, D.; RESENDE, J. C.; LEITE, J. B. et al. A evolução do leite no Brasil em cinco décadas. Revista de Política Agrícola, v. 26, n. 1, Jan./Fev./Mar, 2017.
ZOCCAL, R.; PEREIRA, V. I. F. Panorama do leite. Boletim Eletrônico Mensal, v. 8, n. 85, 2016. Embrapa Gado de Leite-Fôlder/ Folheto/Cartilha, 2015. In: https:// www.infoteca.cnptia.embrapa.br/infoteca/ handle/doc/1038756 (acessado em 04 de setembro de 2017).

Recebido para publicação em 18/7/2018 e aprovado em 25/9/2018. 